\title{
History and science united to vindicate Perutz
}

\author{
A generous team player, he was backed by colleagues in clearing his name over DNA.
}

Sir - Floods of ink, electronic and actual, have been spent on celebrating the fiftieth anniversary of the discovery of DNA's structure, recollecting facts and testimonies from the protagonists (see www.nature.com/ nature/DNA50). A gripping correspondence that I recently uncovered among the papers acquired by Jeremy Norman in Novato, California, adds a further motif of reflection on one much-debated episode.

The facts are well known. André Lwoff of the Pasteur Institute in Paris, reviewing Jim Watson's book The Double Helix (Athenaeum, New York; 1968), highlighted a crucial sentence that implied a breach of faith by Max Perutz, who seemed to have given key scientific material to his colleagues Watson and Crick (Scientific American 219, 133-137; 1968), without permission. Soon after, biochemist Erwin Chargaff denounced Perutz for the same reason (Science 159, 1448-1449; 1968).

The precious information was part of a Medical Research Council (MRC) report that Sir John Randall, director of King's College London, had circulated to all the members of the Biophysics Research Committee, including Perutz, who visited his unit on 15 December 1952. As Watson and Crick both acknowledged, the report, containing Rosalind Franklin's precise measurements, gave them an important clue that helped them unravel the antiparallel nature of DNA and scoop both the
London team and Linus Pauling of Caltech. A year later, Perutz published a rebuttal to Lwoff and Chargaff, in which he described the non-confidential nature of the MRC report (Scientific American 221, 8; 1969 and Science 164, 1537-1538; 1969). Why did it take him so long to respond?

What was not known until now is that Perutz's brief rebuttals were the result of backstage scientific teamwork starting in 1968. This correspondence, which I have now uncovered, offers a fascinating look at a chorus of scientists determined to set an official version of events before the public, and gives an insider perspective on the politics of scientific discovery.

"As you may have gathered," Perutz wrote to a colleague, "I am anxious to correct a story in Watson's book which suggests that I gave Watson and Crick a confidential report... I have now drawn up the enclosed letter which I propose to send to the Scientific American and to Science... Randall, Wilkins, Gosling and Crick have all agreed. So have Lwoff ... and Chargaff. ... Watson is writing an addition to my letter, with an apology for having misrepresented the incident."

Perutz, who died early last year (see Nature 415, 851-852; 2002), was an extraordinary experimentalist, a hard worker at the bench and a cautious man of science. Not interested in the rat race, he just wanted to solve problems. This time, the issue was to prove his innocence. "Watson asked ... why I had not shown the report to [Watson] and Crick immediately," he wrote to Randall. "Was it because I did not want them to get on with the model, etc? And if the report was not confidential, then surely there was no need to ask your permission to show it to them."

Perutz went into the historical evidence, scrupulously interviewing his colleagues and MRC administrators while going through his initial draft, sentence by sentence, to build up a definitive version.

Two letters in particular are worth mentioning. Randall's prompt reaction to being asked whether it was wise to open the lid was to firmly advise leaving it to the historians. Maurice Wilkins, however, took the opposite view, because he thought that science and its discoveries belong to scientists, in the sense that they are the only ones who can fully understand them and therefore say what the true facts are.

To quote the biochemist John Edsall, presenting Perutz's letter to the editor of Science: "An important issue of scientific ethics is involved and the matter should be cleared up not only in order to do justice to Perutz but also because of the influence that this episode may have on other people." Marta Paterlini

Laboratory of Human Neurogenetics, The Rockefeller University, 1230 York Avenue, New York, New York 10021, USA

\section{Were Cro-Magnons too like us for DNA to tell?}

Sir - Your News report "Anthropologists cast doubt on human DNA evidence" (Nature 423, 468; 2003) refers to our study of two 24,000-year-old anatomically modern Europeans, whose mitochondrial DNA sequences were similar to those in today's humans (D. Caramelli et al. Proc. Natl Acad. Sci. USA 100, 6593-6597; 2003). You report views from the community that ancient DNA evidence cannot be used to draw conclusions about the evolution of modern humans because of fundamental problems in the technique.

The criticisms you report are not based on the quality of our study. Neither of the quoted specialists questions our methodology, which was defined by one of them (A. Cooper and H. N. Poinar, Science 289, $1139 ; 2000)$. The problem is in the results.

None of the nine tests we carried out suggests contamination by modern DNA, but the ancient sequences we determined look modern, so there is a suspicion that they are indeed modern, the result of contamination. You report views that the DNA of Cro-Magnons can be studied only if they were different from us. If they had the bad luck to be like us, their sequences must remain unknown forever.

That is an unusual way to conceive science, and one that leads to paradox. If we are to apply this criterion of certainty to other areas, we should have abandoned anaesthesia (it may have side effects), air transportation (planes can fall down), cooked food (it may burn your fingers) and sexual reproduction (you might get AIDS).

If it can be shown that there is an error in our paper, we shall be happy to reconsider our conclusions. Should our results be confirmed, we will be even happier. But if we did all the right things, as seems to be the case so far, it seems irrational to question our study just because one never knows.

Guido Barbujani, Giorgio Bertorelle Department of Biology, University of Ferrara, Via L. Borsari 46, 44100 Ferrara, Italy

\section{Multitude of reference styles delays publication}

Sir - Peter Kareiva et al. make a compelling argument in Correspondence (Nature 420, 15; 2002) that "slow-moving journals hinder conservation efforts". Our appraisal of the 14 journals they assessed shows that time in review is at least partly related to length of reference sections, and citation lists in the three conservation and applied-ecology journals are among the longest. Although many factors affect speed of publication, surely time lost by scientists and scientist-editors on formatting journal-specific reference sections is one of the most frustrating.

There may not be as many reference styles as there are journals, but sometimes this can appear to be the case to a beleaguered author. The considerable time wasted on formatting citation lists into a journal's style is exacerbated by the high likelihood of a submitted paper being rejected and requiring resubmission 
elsewhere, perhaps more than once. The bibliographic software developed to assist with formatting citations only encourages the problem, in that individuals and institutions are compelled to spend their limited money on products that require scientists to spend time learning software rather than doing research. And, of course, the software does not encourage progress toward standardization.

A common citation format, familiar to all, would be sensible. It has been achieved for online versions of papers with the Digital Object Identifier system (DOI), so it should be possible for print journals. Coordination could be undertaken by an organization such as the International Council for Science via its committee on dissemination of scientific information, or the Society for Scholarly Publishing. Certainly, the substance of papers in journals is more important than uniquely stylized references. Time is precious to scientific pursuit, and time wasted retards discovery.

David M. Leslie, Jr*, Meredith J. Hamilton $\dagger$ ${ }^{\star}$ US Geological Survey, Oklahoma Cooperative Fish and Wildlife Research Unit, 404 Life Sciences West, Oklahoma State University, Stillwater,

Oklahoma 74078, USA

$\dagger$ Department of Zoology, Oklahoma State

University, Stillwater, Oklahoma 74078, USA

\section{Writing: visuals are another story}

Sir - Your News Feature "Clear as mud"1 highlights an important issue. The course on effective writing that we run for $\mathrm{PhD}$ students here has taught us that instruction on elements of graphic design (one of us, K.M.F., is a medical illustrator) complements very well the linguistic aspects you address.

We see writing a paper as a business of integrating written and visual information. Scientists are prone to create over-elaborate graphs, charts and other illustrations which inadequately highlight key data. This may actually make a good text more difficult to read. Even when a lot of data need to be included, the manageable information content needs to be taken into account by the author.

For instance, a table containing 17 columns and 7 rows provides necessary documentation but has little visual impact (see, for example, Table 2 of ref. 2). Such tables have greater impact when they are large enough to allow balanced inclusion of text and numerical data (as in Table 1 of ref. 3). Also, complex tables can be made clearer to read by descriptions using full words rather than numerous abbreviations. When experimental results are presented, panels showing single comparisons between control and experimental groups (as in Fig. 4 of ref. 4 ) have a visual advantage over graphs that show multiple experiments on the same axis (see Fig. 3 of ref. 5).

Scientific journals often insist on a very traditional, bland presentation of text and graphics. Perhaps a more creative approach to this on the part of editors would benefit writers and readers alike.

To summarize, before an author submits a paper to a journal, he or she should ask what kind of visual impact it has. Attention to this question would not only improve the paper's readability but would also allow referees to concentrate on data without getting frustrated by the lack of clarity. It might even decrease the rejection rate of essentially good papers. Marek H. Dominiczak, Kathy McFall Medical Humanities Unit, Gartnavel General Hospital, 1053 Great Western Road,

Glasgow G12 OYN, UK

1. Knight, J. Nature 423, 376-378 (2003).

2. Harborne, L., Fleming, R., Lyall, H., Norman, J. \& Sattar, N, Lancet 361, 1894-1901 (2003).

3. Advanced Bladder Cancer (ABC) Meta-analysis Collaboration Lancet 361, 1927-1934 (2003).

4. Golder, M. et al. Lancet 361, 1945-1951 (2003).

5. Sobngwi, E. et al. Lancet 361, 1861-1865 (2003).

\section{Writing: LEX and flexibility}

Sir - In your News Feature on unclear writing, "Clear as mud" (Nature 423, $376-378 ; 2003)$, a passage is cited from the abstract of a paper of which I am first author: "A somitic compartment of tendon progenitors" (Cell 113, 235-248; 2003).

The passage reads: "We demonstrate that the tendons associated with the axial skeleton derive from a heretofore unappreciated, fourth compartment of the somites. Scleraxis (Scx), a bHLH transcription factor, marks this somitic tendon progenitor population at its inception, and is continuously expressed through differentiation into the mature tendons." The News Feature points out that my second sentence begins with a "brand new term", Scleraxis, and quotes writing instructor Judith Swan as suggesting the following rewrite: "This somitic tendon progenitor population is marked at its inception by the gene Scleraxis $(S c x) \ldots$-.. - reasoning that by first recapping the content of the previous sentence, the writer forms a "bridge" or transition that will better prepare readers to take in the new information.

I would first point out that while my second sentence indeed begins with a new term, it makes the transition, just five words later, back to the content of the previous sentence. More importantly, however, my decision to place Scleraxis at the start of the second sentence, and to make it the subject of the sentence followed by an active verb, was to emphasize that it is only because of this marker and its continuous expression that identification of a somitic tendon progenitor population has become possible. Placing this information later in the sentence obscures the gene's importance to the research and cheats the reader of the excitement of discovery of Scleraxis as well as the somitic tendon progenitor population it marks. In short, Swan's preferences, and mine, come down to a question of nuance and style.

While I agree that science writers should strive for clarity, they must be given the same latitude as writers in other disciplines to temper traditional rules of usage with individual stylistic choices that enhance what they want to communicate. Judging papers by methods such as LEX scores, which measure the ratio of everyday words to jargon, is, in my opinion, underestimating the capacity of science readers to creatively and flexibly handle the jargon, stylistic variations, and idiosyncrasies of interesting science writers. In fact, a bit of stylistic license and rule-bending, and a few new terms sprinkled here and there, might even keep the reader curious, challenged and awake. Clarity, yes; but clarity should not be synonymous with absence of style.

\section{Ava Brent}

Department of Genetics, Harvard Medical School, Boston, Massachusetts 02115, USA

\section{Writing: the clear choice}

Sir — It would be interesting to know the accessibility score for G. D. Gopen and J. A. Swan's paper “The science of scientific writing” (Am. Sci. 78, 550-558; 1990), cited in your News Feature about clarity (Nature 423, 376-378; 2003). I use this article in a course I teach. Although it makes some useful points, the students and I think it is overlong and full of unnecessarily complicated words and long-winded sentences.

Writing workshops are great but not widely available. As an alternative, I highly recommend the workbook Essentials of Writing Biomedical Research Papers by Mimi Zieger (McGraw-Hill, New York, 2000) — it works!

Sheila McCormick

Plant Gene Expression Center, USDA/ARS-UC-Berkeley, 800 Buchanan Street, Albany, California 94710, USA

\section{correspondence}

Contributions to Correspondence may be submitted to corres@nature.com. They should be no longer than 500 words, and ideally shorter. 